\title{
A VINCULAÇÃO DE RECURSOS PARA A EDUCAÇÃO E A UDN
}

\author{
WELLINGTON FERREIRA DE JESUS \\ Mestre em Educação pela Universidade Católica de Brasília, Professor de História do \\ Ensino Médio na Rede Pública do Distrito Federal \\ wellingtonfj@gmail.com
}

\begin{abstract}
RESUMO
O trabalho busca identificar a perspectiva do Partido da União Democrática Nacional sobre a educação pública e a vinculação constitucional de recursos, assim como as razões pelas quais os liberais apoiaram essa área protegida do orçamento, apesar de defenderem a liberdade de mercado. Analisa os argumentos favoráveis e contrários à proposição, bem como as restrições ou oposições a ela, no processo legislativo. As fontes examinadas foram os anais e os diários da Assembleia Nacional Constituinte de 1946, além da literatura pertinente. A justificativa da proposição vitoriosa focaliza os limites do Estado do ponto de vista político. Além disso, os membros do partido percebiam que o desenvolvimento industrial do país dependia da expansão da educação primária.

EDUCAÇÃO PÚBLICA - FINANCIAMENTO DA EDUCAÇÃO - ASSEMBLEIA CONSTITUINTE $D E 1946$
\end{abstract}

\section{ABSTRACT}

THE LINKING OF RESOURCES TO EDUCATION AND TO NATIONAL DEMOCRATIC UNION PARTY. The aim of this work is to identify the perspective of the National Democratic Union Party with regard to public education and the constitutional linking of resources, as well as the reasons why the liberals supported this protected area of the budget despite their defense of a free market. It analyses the arguments for and against as well as the restrictions or opposition to it in the legislative process. The sources used were the annals and diaries of the National Constitutional Assembly of 1946, as well as pertinent literature. The victorious proposition is justified focusing on the limits of the State in the political dimension. Furthermore, party members perceived that the industrial development of Brazil depended on expansion of primary education.

PUBLIC EDUCATION - EDUCATIONAL FINANCE - 1946 CONSTITUENT ASSEMBLY

\section{“LENÇOS BRANCOS AO AR!”}

Na década de 1990, um vagalhão neoliberal varreu numerosos países, em todos os continentes do planeta. Num misto de profecia e cinismo, o 
discurso neoliberal apontava o Estado e as políticas sociais como responsáveis diretos pelo imobilismo, por uma crônica inépcia e ineficiência, que resultariam na falência tanto das perspectivas, quanto das possibilidades de desenvolvimento tecnológico, industrial e da superação das barreiras nacionais. Anunciou-se com toda a pompa o "fim da história" e a morte do "paquidérmico" Estado de bem-estar social.

No bojo desse oceano revolto, justificava-se a necessidade das privatizações, da desregulamentação, da liberdade de mercado, da competitividade, da flexibilização do trabalho e do advento de novas "relações entre capital e trabalho". No campo da educação, todo esse discurso foi incorporado e transformado numa referência para atingir a "qualidade total". Afirmava-se que, nesse processo, nada mais lógico do que a efetivação do corte de verbas, de gastos; da desvinculação, ou, pelo menos, "remanejamento estratégico", dos recursos destinados à educação pública para outros fins, "mais imediatos, com retorno concreto". A curtíssimo prazo. Essas medidas se justificavam, segundo os teóricos neoliberais, uma vez que permaneciam elevados os índices de evasão, absenteísmo, repetência, enfim, o "fracasso do sistema público de educação". Eram os tempos da reengenharia.

Contudo, ao nos aproximarmos do final da primeira década do século $X X I$, temos a certeza de que, entre outros aspectos, a história não chegou ao seu final. $\bigcirc$ Estado não morreu, e o corolário neoliberal não se transformou em realidade hegemônica. É possível afirmar atualmente, com base no quadro eleitoral da América Latina e de alguns países europeus, que ocorreu um influxo nesse movimento.

$\mathrm{Na}$ educação, ficaram claras a dimensão e a profundidade das contradições da realidade da escola pública. Reduzir o Estado em um país de contrastes, de tamanho planetário, como o Brasil, representava a destruição das perspectivas de transformação social e intergeracional de milhões de cidadãos, do presente e de um futuro não tão distante. Com as pressões da sociedade, ocorreu um refluxo, no sentido dos cortes orçamentários destinados à educação pública. Embora também não se tenham efetivado as possibilidades concretas de financiamento à educação, no porte que o país necessita e a arrecadação tributária exige.

Ao refletirmos sobre estas questões, torna-se necessário buscar as origens do pensamento liberal contemporâneo acerca da educação e de seu 
financiamento no Brasil. Em um país onde já se afirmou "que nada mais conservador que um liberal no poder e vice-versa", pretendemos neste trabalho, um estudo exploratório, com base em uma pesquisa histórica nos Anais (Brasil, 1949- 1950) e Diários da Assembleia Nacional Constituinte de 1946 (Brasil, $1933-$ 1936), oferecer subsídios para responder a algumas questões, tais como: Qual foi a visão da União Democrática Nacional - UDN - sobre a educação pública e a vinculação constitucional de verbas? Quais motivos levaram os liberais a apoiar a proteção de recursos, pois defendiam o instituto da liberdade de mercado? Quais os propositores da emenda constitucional que vinculou recursos à educação? A justificativa de aprovação era de ordem técnica, política, educacional ou ideológica? Houve restrições ou oposição por parte dos deputados da UDN quanto a esta emenda? E, ao mesmo tempo, entender qual o papel da UDN no debate educacional e na aprovação da emenda constitucional que restituiu a vinculação de verbas à educação na Carta Magna de 1946.

Consideramos que, nas respostas a tais questões, estão elementos que podem ratificar a existência de um processo histórico "como tragédia", no qual o projeto liberal-democrático de oposição à ditadura do Estado Novo de Vargas, o "lenço branco", cedeu lugar a uma estratégia golpista que resultou na ditadura militar de 1964. E, posteriormente, a repetição, agora "como farsa", mediante discurso do Estado como fator de atraso e, especificamente, da educação pública e de seu financiamento como responsáveis pelo definhamento das possibilidades de desenvolvimento do Brasil.

\section{A UDN E O PROCESSO DE REDEMOCRATIZAÇÃO DO BRASIL (1942-1945)}

A partir de 1942 tem início um processo de mobilização de setores organizados da sociedade pela redemocratização do país, que levaria ao esgotamento da ditadura do Estado Novo (1937-1945). A entrada do Brasil na Segunda Guerra e a derrota do nazifascismo precipitaram o processo de distensão interna. Em 1945, um golpe político depôs Getúlio Vargas, em meio a uma onda "continuísta", representada pelo queremismo: "Constituinte com Getúlio!" (Skidmore, 2003), apressando o epílogo da era Vargas. A deposição de Vargas, conforme Souza (1981, p.7), manteve praticamente inalteradas as estruturas econômico-sociais do país. A convocação da Constituinte de 1946 
surge em meio à radicalização do Pós-Guerra entre os Estados Unidos e a, à época, União Soviética. Era a denominada Guerra Fria, que afetaria diretamente o Brasil até o final dos anos 80.

Para a maioria dos estudos (Skidmore, 2003, 2004; Oliveira, Penin, 1986), o período 1946-1964 é visto como uma espécie de aurora da redemocratização, enfatizando mais um processo de descontinuidade do que de permanências. Conforme Souza (1990, p. I 05), no entanto, a Carta de 1946 estabeleceu normas e medidas para instalação de uma estrutura democrática no país, possibilitando uma abertura do processo político até 1964. Entretanto, esse processo de redemocratização teve limites bem definidos a partir de 1947 e, particularmente, com a polarização da Guerra Fria. Além disso, é "compreensível que, situado entre dois períodos reconhecidamente autoritários, o regime 1946-1964 seja considerado pelos seus apologistas, tanto quanto pelos seus detratores, como radicalmente distinto em estrutura e funcionamento". (Souza, 1990, p. I05).

O quadro político-partidário desse período teve suas origens ainda na primeira metade da década de 1940: o referencial histórico inicial é o Manifesto dos mineiros, de outubro de 1943, que desembocaria na formação da UDN.

A partir da segunda metade dos anos 40, assim ficou organizado o quadro político-partidário:

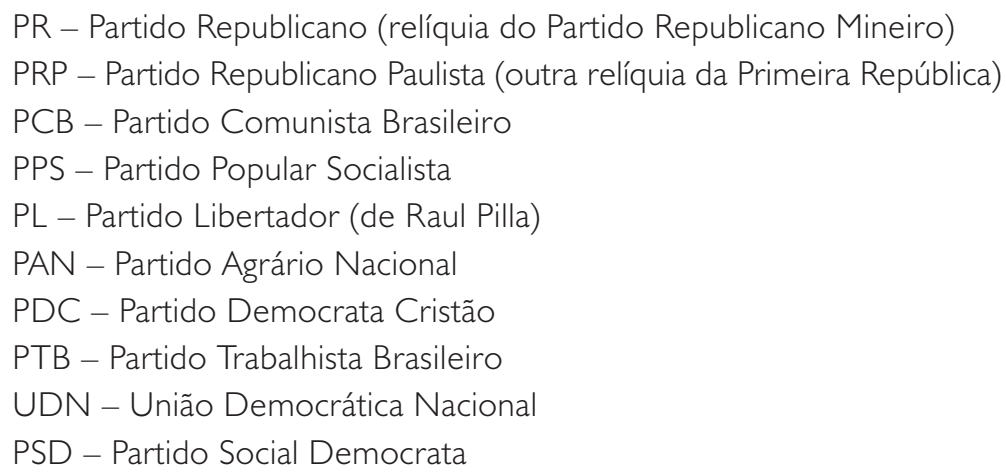

Conforme Skidmore (2003, p.80), a divisão da política brasileira no início de 1945 opunha "os de dentro" e os "de fora". Os "de dentro" eram o PSD e o PTB, os que se achavam "de fora" eram representados de maneira 
mais incisiva pela UDN, enquanto o PCB até a cassação do registro do Partido ficava em posição ambígua, com uma parcela apoiando Vargas e disputando o espaço do PTB com o operariado. Dessa forma, pode-se observar que o cenário político-partidário do período | 946- 1964 terá uma predominância dos denominados "grandes partidos": PSD e UDN. Miceli (1986, p.596) alertou para o fato de que não apenas diferenças ideológicas, mas a base social das alianças definia o papel das diferenças entre a UDN e o PSD.

A UDN foi criada quase concomitantemente ao Manifesto dos mineiros, de 1943. Na realidade, o manifesto representou para a UDN, ao mesmo tempo, a "pedra fundamental" e um "elemento sutil de luta pelo poder" (Benevides, 1981, p.35), na medida em que, ao defender as liberdades civis e o Estado de bem-estar, abriu espaço para a maior presença política e econômica das "elites". O antigetulismo' era a marca do partido, que se organizara como uma composição heterogênea, na qual de um lado havia o grupo dos que se abrigaram sob a candidatura do brigadeiro Eduardo Gomes à Presidência e, de outro, aqueles que não aceitaram a Revolução de 30, ou se sentiram traídos por ela e pela ditadura do Estado Novo. Os lenços brancos eram a sua marca, simbolizando a "luta contra a corrupção" e a pureza dos ideais democráticos e liberais.

Observa-se, pois, que a UDN nasceu sob o signo de uma frente ampla, reunindo, em seu interior, um leque de posicionamentos ideológicos, personagens políticos e tendências históricas diferenciadas. Conforme Benevides ( 1981 , p.29), "Adversários de tempos imperiais, velhos inimigos, desafetos políticos" se uniram e se abrigaram sob o "guarda-chuva" udenista, com o objetivo de apressar a deposição de Getúlio Vargas e a derrubada do Estado Novo. Este grupo que deu origem à UDN era formado por antigas oligarquias, alijadas do poder em 1930; ex-aliados da "primeira hora" de Vargas e "esquecidos" em 1937; membros do Estado Novo que romperam com a ditadura; liberais históricos e, inclusive, alguns integrantes da esquerda (ex-aliancistas, comunistas descontentes com a orientação do partido e intelectuais).

I. Benevides ( 198 |), discutindo a crise de 1954, após o suicídio de Getúlio Vargas, afirma que este era o "principal inimigo - mais do que inimigo, a 'razão de ser de um partido' fundado pelos que se the opunham" (p.90). Em 1955, o deputado Gabriel Passos, na Convenção Nacional da UDN, afirmou que: "Com a morte de Vargas, a UDN parecia uma polia sem correia" (p.9I). 
Segundo Fleischer ( 1981 , p.49), "desta ampla e heterogênea frente antigetulista emergiu a União Democrática Nacional (UDN)" e surgiram as contradições que, no período 1945-1946, levaram a cisões em seu interior. A escolha do brigadeiro Eduardo Gomes como candidato à Presidência em 46 estava ainda longe de ser um consenso. E, "a esta altura, muitos dos integrantes originais da 'frente' haviam se retirado para organizarem seus próprios partidos".

Skidmore (2003, p.86) afirma que a UDN preconizava "uma volta aos princípios do liberalismo, tanto em política quanto em economia (o 'liberalismo' econômico na acepção de Manchester)". Tendo como referência uma política cautelosa de industrialização, buscava a presença do capital estrangeiro, procurava minimizar a presença do Estado na economia, recomendava o cuidado em relação ao Partido Comunista e buscava romper com o que considerava as barreiras impostas no Governo Vargas em relação ao livre curso de homens e capitais (Skidmore, 2003).

Pode-se considerar que, nas origens da UDN, se encontram os elementos que possibilitam a compreensão das transformações pelas quais o partido passou, em pouco mais de uma década e meia. Contrária ao governo autocrático de Vargas, na metade dos anos 40, a UDN transformou-se em polo golpista nos anos 60. Benevides afirmou:

A UDN foi, de fato, um partido político. Embora tenha surgido como um movimento, a UDN organizou-se como partido, e não apenas como uma faç̧ão em luta pelo poder ou um grupo de pressão. Em termos concretos isso significa uma série de considerações sobre a "vida" da UDN. Ao contrário das faç̧ões ou claques a UDN teve uma estrutura permanente e uma organização "burocrática" extensa da cúpula dirigente ao nível municipal em todos os estados do país. Um partido deve promover a mobilização e aspirar o [sic] apoio popular, tanto ao nível dos militares quanto dos eleitores; apesar de sua aura insofismavelmente "elitista", a UDN, através de seus políticos, revelou pretensões expansionistas nos meios populares, conseguidas, muitas vezes, graças a malabarismos "de princípios". (1981a, p.93-94) 


\section{A ASSEMBLEIA NACIONAL CONSTITUINTE DE 1946}

Conforme Oliveira (2000), o contexto histórico do Brasil na instalação da Constituinte de 1946 foi marcado por uma onda de greves que contrariava tanto a posição do PTB quanto a do PC. Em outras palavras, o debate constitucional foi "atravessado pela luta social em curso" (p. I62). Dessa forma, as contradições existentes, sufocadas pela violência do Estado Novo, atingiam um momento de acirramento na segunda metade da década de 1940. Eram necessárias novas concessões à sociedade e a Constituinte teria a tarefa de definir seus parâmetros.

A Assembleia Nacional Constituinte de 1946 foi convocada depois da deposição de Vargas, em 29 de outubro de 1945. Sua convocação foi regulamentada pelas Leis Constitucionais n. 13 ( | 2/I I// 945) e n. I 5 (26/I I// 945), decretadas durante o Governo Provisório de José Linhares. Essas leis determinavam explicitamente que o Congresso (Câmara e Senado) a ser eleito em 2 de dezembro de 1945 teria a "função precípua de elaborar a nova Carta Constitucional, embora durante os trabalhos constituintes permanecesse em vigor a Constituição de 1937" (Braga, 1998, p.36).

Os constituintes, em número de 320, elegeram uma Comissão composta de 36 membros, a Grande Comissão. Esta Grande Comissão foi subdividida em subcomissões, cada qual com a tarefa de elaborar um capítulo da nova Constituição. A composição da Grande Comissão consubstanciava a predominância dos grandes partidos. O PSD tinha 19 representantes, a UDN dez, o PTB dois e os pequenos partidos cinco.

Desta forma, PSD e UDN controlavam e orientavam os itens, artigos e ideias que deveriam constar do texto constitucional (Picaluga, 1980, p.35). Durante o período da Constituinte de 1946, a Carta de 1937 continuou vigorando. A manutenção do texto constitucional outorgado durante o Estado Novo foi aprovada pelos constituintes de 1946 com I 40 votos favoráveis e 90 contrários, sendo que o Partido Comunista e a UDN se posicionaram de maneira contrária.

Conforme a tabela I, o PSD detinha praticamente $66 \%$ do Senado e a maioria absoluta na Câmara Federal. A combinação dessas maiorias resultou para o partido na consolidação da maioria também na Assembleia Constituinte. As "sobras" foram destinadas ao partido que obtivesse a maior votação. Como 
exposto, o PSD conseguiu organizar-se nacionalmente e, combinados esses fatores ao predomínio da máquina eleitoral, configurou sua hegemonia.

\section{TABELA I}

DISTRIBUIÇÃO PERCENTUAL DE VOTOS VÁLIDOS POR PARTIDO PARA OS MEMBROS DA CÂMARA FEDERAL E COMPOSIÇÃO PARTIDÁRIA DA CÂMARA RESULTANTE DA CÂMARA FEDERAL, DO SENADO E DA ASSEMBLEIA CONSTITUINTE DE 1946

\begin{tabular}{lrrrr}
\hline Partidos & $\begin{array}{c}\text { Votos populares } \\
\text { para a Câmara }\end{array}$ & $\begin{array}{c}\text { Senado } \\
\text { Federal }\end{array}$ & $\begin{array}{c}\text { Câmara } \\
\text { Federal }\end{array}$ & \multicolumn{2}{c}{$\begin{array}{c}\text { Assembleia } \\
\text { Constituinte de 1946 }\end{array}$} \\
\hline PSD & $42,7 \%$ & $62,0 \%$ & $53,0 \%$ & $54,0 \%$ \\
UDN & $26,6 \%$ & $24,0 \%$ & $27,0 \%$ & $26,0 \%$ \\
PTB & $10,2 \%$ & $4,7 \%$ & $7,6 \%$ & $7,5 \%$ \\
PCB & $8,6 \%$ & $2,3 \%$ & $4,9 \%$ & $4,7 \%$ \\
OUTROS PARTIDOS & $11,8 \%$ & $7,0 \%$ & $7,5 \%$ & $7,3 \%$ \\
\hline & $100 \%$ & $100 \%$ & $100 \%$ & $100 \%$ \\
\hline
\end{tabular}

Fonte: Souza (1990, p. 123).

Outro aspecto singular que merece destaque quando analisamos a composição da Constituinte de 1946 se refere à formação acadêmica dos constituintes. A maior parte era diplomada em Direito $(55,3 \%)^{2}$, o que significa um indício adicional da influência do chamado "bacharelismo" na formação das lideranças políticas brasileiras do período, embora nem todos os bacharéis em Direito exercessem a profissão de advogados, ao menos como atividade principal. Podemos notar também que, não obstante o menor desenvolvimento da educação superior brasileira em meados dos anos 40, a Constituinte de 1946 apresentava uma porcentagem maior de parlamentares com curso superior (Braga, 1998, p.79). О PCB era o único partido cuja maioria dos deputados não possuía curso superior. Constatamos também a inexistência de mulheres entre os 338 constituintes de 46 e um único deputado negro, Claudino Silva, eleito pelo PCB do Rio de Janeiro. Esse aspecto reforça a discussão sobre a amplitude democrática do período | 946- 1964 e

2. Porcentagem superior à dos constituintes de 1987-1988 (43,4\%). 
a dimensão do controle do Estado e dos mecanismos institucionais por parte de um pequeno setor social do país, praticamente de forma ininterrupta desde suas origens coloniais.

\section{A EDUCAÇÃO NO CONTEXTO DA CONSTITUINTE DE 1946}

No debate sobre a educação, a Constituinte de 46 retomava alguns dos pontos mais polêmicos da Constituição de 34. A orientação de cunho autocrático da ditadura do Estado Novo transformara a educação em um aparelho a serviço dos interesses e necessidades do Estado e do culto à personalidade de Vargas. A visão de uma educação disciplinadora, pilar de uma sociedade corporativista, pensada pelos setores conservadores desde a década de 20, assumira forma concreta no período 1937- 1945.

$\mathrm{Na}$ Assembleia Constituinte de 1946 era necessário retomar o sentido da educação como "direito público subjetivo" (Boaventura, 2000), retomar a diferenciação entre instrução e educação, reorganizar e redefinir os papéis dos entes federativos, repensar a dimensão filosófica e pedagógica da educação, entre outros aspectos.

Significativamente, a transição de um Estado centralista e autocrático, em que o Poder Executivo, personalizado na figura de Vargas, era a única forma de gerenciamento e administração para uma nova forma de organização política em harmonia e independência entre poderes, passava pela questão tributária. E, no caso específico, pela rediscussão do financiamento da educação. A Carta de 1946 recuperou o instrumento da vinculação de recursos à educação. Conforme Oliveira:

... a vinculação foi reintroduzida no início dos anos 40. Esse fato teria ocorrido "como consequência da Conferência Interestadual de Educação", que "propôs a criação de um Fundo Nacional do Ensino Primário - instituído pelo DecretoLei n. 4.958, de 1942" - e do Convênio Nacional do Ensino Primário. […] Esse Convênio do Ensino Primário, ratificado pelo Decreto-Lei n. 5.239/43, assinalava o "compromisso dos Estados signatários de aplicarem, em educação, no ano de 1944, 15\% da receita de impostos e os municípios 10\%". Os referidos percentuais deveriam aumentar "em $1 \%$ ao ano até atingirem a marca de $20 \%$ e 15\%, respectivamente no ano de 1949". Já os recursos que 
constituiriam o referido Fundo teriam sua fonte "num adicional de 5\% sobre as taxas do imposto de consumo de bebidas" que, por sua vez, havia sido criado em 1938. (Apud Ramos, 2003, p.239).

Em síntese, é possível considerar que a questão da oposição entre público versus privado predominou nos debates da Assembleia Constituinte de 1946, sobre educação, sob a perspectiva da discussão que contrapunha ensino religioso a ensino laico. Essa questão limitava, embora não subdimensionasse, uma visão mais abrangente do debate sobre as questões estruturais da educação nacional. Em outras palavras, a solução para os problemas emergenciais, como a questão da universalização e democratização do ensino, do dimensionamento de um conjunto de diretrizes básicas educacionais e do próprio financiamento da educação, foi postergada e só se concretizou, quinze anos após a promulgação da Constituição (Oliveira, 2000), com a Lei de Diretrizes e Bases da Educação Nacional e o Plano Nacional de Educação.

O anteprojeto apresentado à Assembleia Constituinte de 1946 teve por base a Constituição de 1934. Após as discussões e emendas ao Projeto primitivo e, posteriormente, Projeto revisto, o deputado Gustavo Capanema apresentou um substitutivo (Substitutivo Capanema) ao Capítulo da Educação, que resultaria em alterações na estrutura deste. Depois de alguns debates, o Substitutivo Capanema foi fundido no texto dos artigos 167, 168 (incisos I e VII), I7I e 172 da redação final.

Outro aspecto dos debates versou sobre a responsabilização da família como coparticipante do desenvolvimento do processo de educação. Em outras palavras, o eixo do debate era "Estado x Família: o dever e o direito de educar" (Oliveira, 2000, p. 175), além da questão da liberdade de ensino e da "ação supletiva da União".

Um debate significativo foi travado sobre a "liberdade de ensino e oficialismo". Em outras palavras, o anteprojeto determinava que coubesse ao Estado a competência sobre as diretrizes do ensino, no entanto, diversos constituintes apresentaram emendas no sentido da extensão das responsabilidades ao setor privado. De tal forma que o deputado Pedro Vergara (PSD-RS) apresentou uma emenda considerando o ensino primário particular como "atividade pública" nas áreas em que não houvesse a presença do setor público. Ao final da Assembleia Constituinte, foi aprovada a abertura 
de responsabilidades ao setor privado, como uma vitória da "força dos conservadores" (Oliveira, Penin, 1986, p.273).

Uma das questões mais polêmicas, contudo, na Assembleia Constituinte de 1946, teve como epicentro as responsabilidades dos entes federativos na administração pública com relação à educação. Três propostas dominaram os debates: a existência de um Sistema Nacional de Ensino, cabendo à responsabilidade da União e, aos Estados e Municípios, "suprir as deficiências locais"; a segunda proposta tinha como base a admissão de dois grandes sistemas de ensino, federal e estaduais e, por fim, a proposta pela qual cada "nível de administração pública organizará seu próprio sistema de ensino" (Oliveira, 1990, p. 100).

Os constituintes que atuaram na defesa ou na contraposição de qualquer das três propostas apresentadas entrecruzavam várias concepções e argumentos. Havia uma visão "municipalista", na qual a função educativa deveria estar a cargo dos municípios como "forma mais próxima de colocar o ensino nas mãos de particulares" (Oliveira, 1990, p. 100). Outra visão tinha como princípio que a competência de legislar sobre educação pertenceria basicamente à União, devendo esta definir o que caberia a cada um dos demais níveis de administração pública. Por fim, havia uma concepção pela qual, em razão da tradição jurídica (Oliveira, 1996), caberia aos estados a responsabilidade pelo ensino fundamental e médio.

Após os debates, emendas e votações, ficou estatuído nos artigos $5^{\circ}$, $6^{\circ}, 171^{\circ}$ e $172^{\circ}$ que cabia à União legislar sobre as diretrizes e bases da educação nacional. Essa competência da União não excluía a legislação estadual "supletiva ou complementar". Ainda constituía responsabilidade da União a organização do sistema federal de ensino e dos territórios (art. 170). No parágrafo único do art. 170, era determinado que: "O sistema federal de ensino terá caráter supletivo, estendendo-se a todo o País nos estritos limites das deficiências locais".

Sobre a competência dos demais entes federativos, o art. |7| determinou que os estados e o Distrito Federal organizassem os "seus próprios sistemas de ensino" e, no parágrafo único, era estabelecido que: "Para o desenvolvimento desses sistemas a União cooperará com auxílio pecuniário, o qual, em relação ao ensino primário, provirá do respectivo Fundo Nacional" (Cunha, 200।, p.210-25।). 
Com relação ao nanciamento para a educação, nas discussões da Assembleia Nacional Constituinte de 1946, podemos a rmar que se tratou de um dos assuntos mais polêmicos, gerando debates intensos e acalorados. Os debates sobre esse aspecto foram iniciados tomando-se como referência a Carta de 1934, mas, ao longo do processo de discussão, assumiram uma dimensão que integrava as questões e contradições nacionais ao quadro de crise da educação. Em outras palavras, a discussão do nanciamento foi compreendida dentro da dimensão da educação integrada à noção do direito público subjetivo, mecanismo de promoção de mudança social e de fator de desenvolvimento nacional.

O Projeto Primitivo propunha a aplicação do percentual mínimo de 20\%, para a União e os municípios, da receita dos impostos para a manutenção e desenvolvimento do ensino. E determinava ainda a reserva de $20 \%$ das quotas destinadas à educação nos seus orçamentos, por parte da União, para o ensino nas áreas rurais.

O eixo dos debates estava centrado em três posições principais: a posição contrária à vinculação, a proposta de criação de um imposto exclusivo destinado à educação e a defesa da vinculação, incluída a questão do quantum a ser vinculado.

Entre os argumentos contrários à vinculação encontramos um aspecto singular: não havia uma posição enfática de condenação a esta, como os argumentos de "esclerose" (cf. Gomes, 1996) ou "engessamento"3 do orçamento, mas se discutia a possível não efetivação concreta do dispositivo. Em outras palavras, a vinculação não seria respeitada e não existiriam sanções ou punições à violação da Constituição (Oliveira, 1990, p. 91).

Com relação à proposta de "criação de um imposto exclusivo" destinado à educação, destacou-se a atuação do professor Sud Mennucci, em uma carta enviada à Assembleia, em 13 de junho de 1946 (Anais, v. I 2), lida em plenário e defendida pelo deputado José Augusto (UDN-RN).

\section{OS DEBATES SOBRE A VINCULAÇÃO DE VERBAS À EDUCAÇÃO}

O tema vinculação de verbas foi retomado na Assembleia Constituinte de 1946 a partir da experiência histórica da Constituição de 1934. Se, em

3. Argumento defendido pelos economistas neoliberais dos anos 90. 
1934, não houve um acirrado embate nesta questão, em 1946 o tema foi debatido com uma profundidade e amplitude que retomava as propostas dos "renovadores", a situação de manutenção das desigualdades regionais e socioeconômicas, a experiência histórica do autoritarismo do Estado Novo e a visão liberal que predominava no processo de consolidação do capitalismo no país (Oliveira, apud Ramos, 2003, p.234).

Mas a "reintrodução" a que se refere Oliveira ocorre apenas mediante decretos-leis e, na verdade, no texto constitucional ela só reaparece por ocasião da promulgação da Constituição Federal de 1946, quando o processo de redemocratização assegura novamente a vinculação de verbas para a educação diante da crescente mobilização social. $\bigcirc$ eixo central que norteou a discussão sobre a vinculação referiu-se ao quantum a ser vinculado. Segundo Oliveira:

As diferentes propostas do 'quantum' a ser vinculado são arbitrárias, não se sustentam em análise das necessidades da educação nacional, nem na distribuição desse montante entre os diferentes níveis de ensino. [...] Um parâmetro norteador do 'quantum' a ser vinculado para cada esfera era a possibilidade efetiva de seu cumprimento. É por isso que a vinculação da União, inicialmente xada em $20 \%$, é reduzida, na própria Comissão de Constituição, para 10\%. (1996, p. I83)

Além da discussão sobre percentuais a serem alocados pelos entes federativos, também integrou os debates o papel prioritário da destinação destes recursos voltados em especial à educação primária e aos alunos considerados carentes.

Na realidade, nas diferentes propostas apresentadas em relação ao percentual a ser vinculado, não se consideravam as necessidades reais da educação ou a divisão equitativa entre União, estados e municípios (Oliveira, 1990). E nem mesmo o porquê de tais valores e se havia a possibilidade de uma ampliação destes (Oliveira, 2000). Este critério arbitrário em relação ao quantum a ser vinculado foi observado pelo deputado Prado Kelly:

Sabe V. Exa. que nos orçamentos se prevê a estimativa de despesa quando não se torna imprescindível; isto posto, vão se buscar os recursos para compor a receita. Neste caso, o que sustentamos é que, dentre todos os serviços da União, uma quinta parte incumbe à educação. O critério é mais ou menos arbitrário, mas 
é a fórmula que obriga aos governantes da União, Estados e Municípios a encarar e resolver o assunto. (grifo nosso, Anais, v. I0)

Destaca-se que no projeto primitivo o percentual de vinculação da União era de 20\%, mas foi reduzido na Comissão de Constituição para $10 \%$ em razão de que "o parâmetro norteador do 'quantum' a ser vinculado para cada esfera era a possibilidade efetiva de seu cumprimento" (Oliveira, 1996, p.92).

Gustavo Capanema, ao apresentar o seu Substitutivo, tomando por referência a Carta de 1934, afirmou que estabelecer o percentual de 20\% para a União era levar à "desmoralização do preceito constitucional”. Entretanto, segundo o mesmo deputado, era necessário evitar "trabalhar contra a educação nacional", estabelecendo um "limite baixo", que poderia ser visto como "uma espécie de teto obrigatório" (Anais, v. I2). Resultando disto a redação "nunca menos de" no texto constitucional.

\section{AS EMENDAS SOBRE A VINCULAÇÃO DE VERBAS À EDUCAÇÃO}

Em 5 de junho de 1946 era proposta a Emenda n. 120, subscrita pelos deputados João Botelho, Magalhães Barata, Moura Carvalho, Nelson Parijós, Álvaro Adolfo, Duarte de Oliveira (PSD-PA), Leopoldo Perez, Waldemar Pedrosa (PSD-AM) e Crepori Franco (PSD-MA), que propunha a vinculação de verbas à educação na Carta de 1946:

Ao Art. 138.

Redija-se por esta forma o artigo 138:

Art... "A União e os Territórios aplicarão, anual e obrigatoriamente dez por cento, e os Estados, o Distrito Federal e os Municípios, vinte por cento, da renda resultante dos impostos, na manutenção e desenvolvimento do ensino primário, técnico-profissional e secundário obrigatórios, gratuitos os dois primeiros."

Acrescente-se ao artigo o parágrafo único seguinte, defendido pela Constituição de 1934:

Parágrafo único - "Para a realização do ensino nas zonas rurais, a União reservará, no mínimo, vinte por cento das cotas destinadas à educação no respectivo orçamento anual". (Anais, v. II, p.33) 
O texto de justificativa da Emenda n. 120 recorria ao "problema" do ensino, "principalmente nos três graus: primário, técnico-profissional e secundário", dada a necessidade da universalização e expansão de forma pública e gratuita. Alertava para o fato de que a emenda corresponsabilizava também os territórios, retirando uma sobrecarga a mais da União. Fazendo referências a Pontes de Miranda e Tavares Bastos, o texto da justificativa da emenda reafirmava a crença na ideia de que "a educação igual eleva" e chamava a atenção para as transformações de cunho social e econômico, a passagem da sociedade rural para a realidade urbano-industrial e suas necessidades. Afirmava que "o ensino, esse agente invisível, que centuplicando a energia do braço humano é sem dúvida a mais poderosa das máquinas de trabalho" (Anais, v. II).

Os deputados José Romero e Jonas Correa (PSD-DF) apresentaram, em 10 de junho de 1946, a Emenda n. 298 - aditiva ao parágrafo 31 do artigo 164: "O ensino, em todos os graus, será gratuito para os brasileiros pobres" (Anais, v. 12). A justificativa apresentada consistia no fato de que, sendo apenas o curso primário obrigatório, cabia ao governo promover o ensino gratuito de "humanidades e universitário" aos alunos que comprovassem não dispor de condições e recursos. Afirmavam que "não é equitativo" o governo oferecer apenas o curso primário, deixando de ofertar "cursos mais custosos", pois era tarefa do Estado amparar estudantes pobres que desejavam servir à pátria e alertavam para o fato de que os estudantes militares dispunham de escola gratuita e "recebiam mesadas e outras vantagens".

O deputado Agrícola de Barros (UDN-MT), em II de junho de 1946, apresentou a Emenda n. 387-A com a ressalva de estar no Capítulo 3, "Dos direitos sociais". Defendeu a obrigatoriedade e a gratuidade do ensino primário, urbano e rural, e a gratuidade do "ensino ginasial e superior" em todos os seus "ramos e graus". Em sua justi cativa fez as seguintes considerações: o grande percentual de analfabetos, o elevado percentual de "talentos que caram perdidos" por não poder continuar os estudos, a necessidade de o Estado amparar "todos os seus Ihos" e aproveitar em benefício próprio "as inteligências que caram perdidas sem escolas superiores" e, por m, os inúmeros "brasileiros ilustres que saíram das classes desprotegidas e pobres, graças aos auxílios do Governo" (Anais, v. 12).

A Emenda n. 473, apresentada pelo Deputado Brígido Tinoco (PSD-RJ), elevava os percentuais da União a 15\% e o dos estados, Distrito Federal e 
municípios, ao mínimo de $25 \%$ da receita arrecadada na manutenção e desenvolvimento do ensino. Também subvinculava 10\% do percentual da União e I 5\% dos estados e municípios para o "ensino primário e técnico-profissional" (Anais, v. 12). Essa emenda gerou um dos momentos de maior intensidade nos debates sobre a vinculação na Assembleia de 1946. Citando o educador Lourenço Filho, Brígido Tinoco afirmou que havia a necessidade de disseminar escolas primárias por todo o país e fez críticas ao sistema tributário brasileiro, conclamando a Assembleia Constituinte a verificar a situação do ensino primário (Anais, 1946, v. 10). Aparteado, em seu discurso de justificativa pelo deputado Aureliano Leite (UDN-MG), que afirmava ser "pouquíssimo" o percentual, Brígido Tinoco afirmou que: "Temos 50\% de analfabetos. Consumimos apenas 500 milhões de cruzeiros com a instrução quando deveria ser, pelo menos, um bilhão", ao que o deputado Aureliano Leite reafirmou ser esta a "razão do nosso atraso em matéria de instrução primária". (Anais).

Nesse momento, o deputado Ferreira de Souza (UDN-RN), da Comissão de Educação, afirmou que, embora "louvando a iniciativa do nobre colega, entende que deve ser mantido o critério obstado igualmente traduzido na emenda (sic) Capanema". Segundo Ferreira de Souza, a obtenção do percentual de 10\% da renda da União consistiria em um "grande passo", pois não existiam recursos disponíveis para a educação em todos os níveis. $\bigcirc$ deputado Tinoco, em aparte, recorda que "todas as nações do mundo reservam para esse fim [educação] 20, 30 e 40\%" e o Brasil "não chegara a tal ponto". Ferreira de Souza, embora reconhecendo a validade da emenda, afirmou que não se podia dispor de maneira absoluta do orçamento e fixar percentagens rígidas era "manietar o legislador ordinário". O deputado Aureliano Leite, intervindo no debate, afirmou que: "O vergonhoso atraso da instrução primária no Brasil reclama esse sacrifício", ao que Ferreira de Souza retrucou afirmando que: "Não sei se o atraso da instrução primária no Brasil é desse molde...". Aureliano Leite afirmou que o Brasil estava em último lugar na América do Sul no contexto da educação (Anais).

Ferreira de Souza reafirmou que a Emenda Capanema não fixava o percentual de 10\%, mas "pelo menos 10\%". Declarando que não era possível realizar "novas reservas, acabaremos absorvendo toda a renda orçamentária, destinando-a a fins especiais" e impedindo ao legislador ordinário de organizar a matéria orçamentária, formulou votos para que a proposta de Brígido 
Tinoco fosse "considerada pelo legislador ordinário e se incorpore à política de educação do Brasil", mantém a Emenda Capanema (Anais). Em votação, a Emenda n. 473, de Brígido Tinoco, foi rejeitada.

Subscrita pelos deputados João Cleofas (UDN-PE), Alde Sampaio (UDN-PE), Gilberto Freyre (UDN-PE), João Ursulo Ribeiro Coutinho (UDNPB), Dolor de Andrade (UDN-MT) e Lima Cavalcanti (UDN-PE), em 8 de junho de 1946, a Emenda n. 559 propunha que a União mantivesse as "escolas modelo, de tipo rural" com o objetivo de erradicar o analfabetismo e difundir o ensino técnico-profissional no "interior" (Anais, v. 13, p.77). Na argumentação que justificava a emenda era apresentado um histórico desde a Carta de |891, que transferia aos estados e municípios a tarefa de arcar com o custeio da instrução primária. Em razão das novas exigências da educação e das receitas dos estados e municípios estarem em baixa, caberia à União "ao menos a ação complementar", concorrendo com parte de seus recursos para "reabilitar pela educação e instrução, os muitos milhões de brasileiros" (Anais).

Uma emenda curiosa, pelo caráter de conceituação e entendimento de "família numerosa" e, sobretudo, pela dimensão assistencialista em relação às obrigações do Estado para com a sociedade e a família, foi apresentada pelo deputado Novaes Filho (PSD-PE). Em 12 de junho de 1946, a Emenda n. 72 I determinava "onde convier", a gratuidade em "qualquer dos seus graus" do ensino para as "famílias numerosas", tomando como referência o total igual ou superior de oito filhos como para definição dessa mesma (Anais). Argumentava o deputado que era dever do Estado a assistência à família, particularmente no sentido da promoção do ensino gratuito. Segundo o parlamentar, muitas vocações "se perdem no anonimato" das áreas rurais e urbanas, sem frequentarem as escolas em razão do "ônus do primário e [...] das largas despesas" com uniforme, material escolar, mensalidades, taxas de exames, "joias de matrículas". A presença do governo evitaria que "gerações inocentes morram na juventude, entregues sem aviso à indisciplina do vício e do abandono." (Anais).

O deputado César Costa (PSD-SP) apresentou um requerimento com o objetivo de subvincular 20\% dos recursos à educação para o ensino rural, conforme o artigo I 56 da Constituição de 1934. A proposta sequer chegou a constar do Projeto Revisto. Desta forma, nem foi submetida a voto. 
A proposta de vinculação constitucional de verbas para a educação começou a tomar corpo a partir de 19 de junho de 1946, quando foram apresentadas duas emendas que discutiam o tema de forma mais estruturada. A primeira emenda, de n. 2.978, determinava que anualmente a União aplicasse nunca menos de $20 \%$ e os estados, Distrito Federal e municípios nunca menos de $40 \%$ do "resultado dos impostos na manutenção do ensino, da saúde, e rodovias" (Anais). Não apresentava, portanto, uma divisão dos percentuais destinados a cada setor, mantendo a estrutura anterior, em que os recursos ficavam a critério do mandatário. Apresentada pelos deputados Fernando Telles (UDN-CE), Epílogo de Campos (UDN-PA) e assinada por Egberto Rodrigues, Gentil Moreira, Alencar Araripe, Leão Sampaio, José de Borba (UDN-CE), José Candido (UDN-PI), Alerico Pacheco (UDN-MA), Moreira da Rocha, Almeida Monte, Frota Gentil, Oswaldo Studart (PSD-CE), João Aguiar (PSD-PR), José Alves Linhares (PPS-PSP/CE) e Lino Machado (PR-MA), a justificativa era baseada nas necessidades da educação, saúde e infraestrutura, como função precípua do Governo. Citando Cícero, os autores afirmaram serem essas medidas salus populus suprema lex est.

Todavia, a emenda que foi a base definidora do artigo que estatuiu a vinculação de verbas à educação foi a de n. 2.984 (24/06/I 946), apresentada por Max Tavares d'Amaral (UDN-SC) e assinada pelos deputados Thomas Fontes (UDN-SC), Raul Pilla (PL-RS), Altino Arantes (PR-SP), José Bonifácio, Lycurgo Leite (UDN-MG), Euclides de Figueiredo (UDN-DF), Romeu Lourenção (UDN-SP) e Osório Tuyty (UDN-RS). Apresentava em seu texto a seguinte modificação ao art. 138 do anteprojeto: "Anualmente aplicarão [sic], a União e os Municípios nunca menos de dez por cento e os Estados e o Distrito Federal nunca menos de vinte por cento da renda resultante dos impostos em manutenção e desenvolvimento do ensino" (Anais, v. 19). Na justificativa argumentava sobre a necessidade da educação como fator fundamental ao país, mas, tendo por referência o Estado de Santa Catarina, Max Tavares D'Amaral e os demais signatários da emenda alertavam para o fato da sobrecarga nos municípios e da obrigação com a saúde e o desenvolvimento de obras públicas. Dessa forma, era observada a necessidade da equidade entre os entes federativos.

Por sua vez, a emenda n. 3249, de 24 de junho de 1946, proposta pelo deputado Jarbas Maranhão (PSD-PE), apresentava quase que uma nova redação 
ao capítulo da educação, com a vinculação dos percentuais de $10 \%$ para a União e os municípios e $20 \%$ para os estados e o Distrito Federal da arrecadação dos impostos destinados à manutenção do ensino. Além disso, essa emenda determinava o auxílio da União aos estudantes pobres no ensino secundário e superior e o apoio nanceiro às escolas rurais (Anais, v. 16).

Observando a correlação partidos/região-emendas favoráveis à vinculação, conforme a tabela 2, constatamos um predomínio dos denominados "grandes partidos", UDN e PSD, na apresentação e participação dos deputados desses partidos nas emendas pesquisadas.

TABELA 2

DISTRIBUIÇÃO DO NÚMERO DE DEPUTADOS QUE APRESENTARAM EMENDAS SOBRE A VINCULAÇÃO DE PERCENTUAIS DA ARRECADAÇÃO DE IMPOSTOS À MANUTENÇÃO DO ENSINO POR PARTIDO POLÍTICO E REGIÃO**

\begin{tabular}{lrlr}
\hline $\begin{array}{l}\text { Partido } \\
\text { político }\end{array}$ & $\begin{array}{r}\text { n. de } \\
\text { deputados }\end{array}$ & Região & $\begin{array}{r}\text { n. de } \\
\text { deputados }\end{array}$ \\
\hline UDN & 23 & NORTE (AC, AM, PA) & 9 \\
\hline PSD & 19 & NORDESTE OCIDENTAL ** (MA, PI, CE, RN, PB, PE, AL) & 22 \\
\hline PR & 2 & CENTRO-OESTE (GO, MT) & 2 \\
\hline PL & 1 & MERIDIONAL (MG, ES, RJ, DF) & 5 \\
\hline PPS-PSP & I & SUL (SP, PR, SC, RS) & Total \\
\hline Total & 46 & & 46 \\
\hline
\end{tabular}

Fonte: Anais da Constituição de 1946 (elaboração própria).

* Conforme divisão regional do Brasil em 1946.

** A Região Leste Setentrional (SE, BA) não apresentou senadores ou deputados com propostas de emenda para a vinculação ao setor educacional.

Promulgada a Constituição de 1946, o capítulo sobre a educação era composto de apenas sete artigos. $\bigcirc$ artigo sobre a vinculação assim cou definido:

Art. 169 - Anualmente, a União aplicará nunca menos de dez por cento, e os Estados, o Distrito Federal e os Municípios nunca menos de vinte por cento da renda resultante dos impostos na manutenção e desenvolvimento do ensino. [...] 
Art. 171 - Os Estados e o Distrito Federal organizarão os seus sistemas de ensino.

Parágrafo único - Para o desenvolvimento desses sistemas a União cooperará com auxílio pecuniário, o qual, em relação ao ensino primário, provirá do respectivo Fundo Nacional. (Diários, 1946, n. I6I, p.5.104)

\section{CONSIDERAÇÕES FINAIS}

A Assembleia Nacional Constituinte de 1946 retomou a discussão e a proposta de vinculação constitucional de verbas à educação originada em 1933-1934 e a consolidou como integrante do contexto do "direito público subjetivo" e das necessidades de organização e financiamento dessa estrutura. $\bigcirc$ artigo 169, da Carta Magna de 1946, determinava que a União aplicasse nunca menos de $10 \%$ e os demais entes federativos, nunca menos de $20 \%$ da receita resultante dos impostos na manutenção e no desenvolvimento do ensino.

Manteve, entretanto, as contradições e fragilidades da proposta anterior: o percentual de recursos alocados era o mesmo, em um país com um crescimento populacional e urbano acelerado e necessidade de democratização e universalização do ensino público. Não eram definidos mecanismos de fiscalização, controle e mesmo punição para o descumprimento da lei, bem como a distribuição entre os níveis e modalidades. De forma implícita mantinha-se a divisão entre a educação das "classes populares", de nível primário, e dos setores médios e das "elites", ensino secundário e educação superior. $\bigcirc$ equilíbrio e a dimensão equitativa entre os entes federativos foi objeto de discussão, tendo como referência a questão tributária e, de forma secundária, as necessidades ou ações efetivas de cada ente federativo.

Podemos observar que as emendas apresentadas convergiam no sentido da necessidade dos recursos protegidos para a educação em sua essência. Apresentavam algumas divergências quanto à redação e, em poucas situações, com relação aos valores e responsabilidades dos entes federativos. Nas argumentações que funcionavam como base para as justificativas, a educação era vista como o "problema nacional", conforme a visão de Miguel Couto, autor da emenda que instituiu a vinculação em 1934, e dos Pioneiros de 32. Observavam a necessidade de investimentos na erradicação do analfabetismo e 
garantia do ensino público, para alguns deputados em todos os níveis gratuito. A Emenda n. 2.984, que funcionou como o substrato para o artigo da Carta de 1946, apresentava também a problemática que envolve a equidade entre os entes federativos.

O destaque central é a maior presença de constituintes da UDN, apresentando ou assinando as emendas, 23 contra 19 do PSD. Inclusive a Emenda de n. 2.984 foi apresentada por Tavares D'Amaral, deputado pertencente à UDN-SC. Formado pela Faculdade de Direito de São Paulo em 1930, Tavares D’Amaral foi promotor público em Santa Catarina em 1931 e abandonou o cargo para dedicar-se à advocacia no interior do estado. A Constituinte foi a sua primeira legislatura e concentrou sua atuação na abordagem de questões referentes à autonomia municipal e na defesa da extinção do Território do Iguaçu e da denominação de "língua portuguesa" para o idioma falado no Brasil, tendo participado de diversos debates em plenário sobre esses assuntos. Ocupou a tribuna para proferir discursos justificando emendas de sua autoria que concediam maior autonomia financeira e administrativa aos municípios (Braga, 1998).

Outro aspecto a considerar reside no fato de que a maioria dos constituintes que apresentaram, defenderam ou subscreveram as emendas que determinavam a vinculação à educação era de pro ssionais liberais (advogados, professores universitários, jornalistas) e, também, de proprietários de terra e pecuaristas, reforçando a permanência do traço oligárquico modernizado ou não pelas mudanças sociais e econômicas iniciadas nos anos 1920 e consolidadas na década de 40.

De orientação liberal, a preocupação da UDN tem uma clara dimensão de disciplinar a ação do Estado, evitando o controle e o monopólio das verbas destinadas à educação. Desta forma, o exercício de de nição de percentuais e destinação, bem como a veri cação da sua aplicação, estaria sob "o controle da sociedade" e não nas mãos do Estado.

Outro aspecto significativo reside em que 22 parlamentares da região Nordeste participaram da apresentação ou subscreveram emendas ligadas à proteção constitucional de recursos à educação. Pode-se considerar a situação de pobreza, miséria e a crônica ausência do Estado nessa região como um possível fator no sentido da efetiva participação. Todavia, há um aspecto que precisamos considerar no que diz respeito à região Sudeste. $\bigcirc$ país consolidava o processo de transição de uma sociedade agrária em direção a uma realidade 
capitalista urbano-industrial na década de 1940. Conforme diversos constituintes, São Paulo, Rio de Janeiro e Santa Catarina já aplicavam em educação valores superiores aos determinados nas propostas de vinculação à educação, consistindo em alvo de preocupação a possibilidade de uma redução desses valores, baseada no "pretexto de que a Constituição assim o determinava". Chama a atenção o fato de que não houve, por parte dos representantes do Sudeste e Sul, uma defesa enfática no sentido de uma maior presença da União nos recursos protegidos à educação. Outro aspecto a ser observado consiste em que, apesar de liberal, a UDN não se opôs aos recursos protegidos, situação absolutamente inversa aos liberais (ou neoliberais) contemporâneos que enxergam na vinculação constitucional de verbas um fator de ine ciência e ine cácia.

No Brasil contemporâneo chama a atenção o debate sobre o financiamento, bem como a questão da equidade e responsabilidades dos entes federativos no sentido da alocação de recursos ao setor educacional. A década de 1990, marcada pela política de ajuste econômico e diminuição das dimensões do Estado, observou, a partir da criação do Fundo de Manutenção e Desenvolvimento do Ensino Fundamental - Fundef -, um momento significativo de discussão do financiamento à educação pública. Considerando o fato de que, no momento atual, em meio ao processo de efetivação do Fundo de Desenvolvimento da Educação Básica e de Valorização dos Profissionais da Educação - Fundeb -, nada mais oportuno do que discutirmos a vinculação constitucional de verbas para a educação; tanto a significação quanto as dimensões e implicações político-sociais deste mecanismo.

Cabe ressaltar que a UDN, reconhecidamente o DNA histórico do liberalismo brasileiro contemporâneo, em que pese suas posições políticas e econômicas, posicionou-se favoravelmente à instituição da vinculação na Constituinte de 1946. Desta forma, na vigência atual do Estado de direito, não podemos fugir do debate e especialmente da discussão relativa à ampliação desses percentuais vinculados à educação pública brasileira.

\section{REFERÊNCIAS BIBLIOGRÁFICAS}

BENEVIDES, M. V. A UDN e o udenismo. Rio de Janeiro: Paz e Terra, 1981.

A União Democrática Nacional. In: FLEISCHER, D. V. Os Partidos políticos no Brasil. Brasília, I98 Ia. p.91- 108. (Cadernos da UnB, v.2) 
BOAVENTURA, E. M. A Educação na Constituinte de 1946: comentários. In: FÁVERO, O. (Org.). A Educação nas Constituintes brasileiras: 1823-1988. Campinas: Autores Associados, 2000. p.191-199.

BRASIL. Câmara dos Deputados. Anais da Assembleia Nacional Constituinte de 1946. Brasília, 1949-1950. Disponível em: http://www.camara.gov.br. Acesso em: 10 maio 2006.

BRASIL. Diários da assembleia nacional constituinte de 1946. Rio de Janeiro: Imprensa Nacional, 1933-1936. Disponível em: http://www2.camara.gov.br Acesso em: 27 jul. 2006.

BRAGA, S. S. Quem foi quem na Assembleia Constituinte de 1946: um per I socioeconômico e regional da constituinte de 1946. Brasília: Câmara dos Deputados, 1998. 2v.

CALDEIRA, J. Viagem pela história do Brasil. São Paulo: Cia. das Letras, 1995.

CUNHA, A. S. Todas as constituições brasileiras. Campinas: Bookseller, 200I.

FLEISCHER, D. V. O Bipartidarismo. In: FLEISCHER, David V. (Org.). Os Partidos políticos no Brasil. Brasília: Editora da UnB, 1981. p. 183-201. (Cadernos da UnB, v.2)

GOMES, C. A. João Calmon, batalhador da educação. Campinas: Autores Associados, 1996.

MICELI, S. Carne e osso da elite política brasileira pós- 1930. In: FAUSTO, B. (Org.). História geral da civilização brasileira. 3.ed. São Paulo: Difel, 1986. v.3, t.3, p.557-596.

OLIVEIRA, R. P. de. Educação e sociedade na Assembleia Constituinte de 1946. 1990. Dissertação (Mestrado em Educação) - Faculdade de Educação da Universidade de São Paulo, São Paulo.

A Educação na Constituinte de 1946. In: FÁVERO, O. (Org.). A Educação nas constituintes brasileiras: 1823-1988. Campinas: Autores Associados, 1996. p. I53- 190.

OLIVEIRA, R. P. de; PENIN, S. T. S. A Educação na Constituinte de 1946. Revista da Faculdade de Educação, São Paulo, v. I2, n. I/2, p.26I-288, jan./dez. 1986.

PICALUGA, I. F. Partidos políticos e classes sociais: a UDN na Guanabara. Rio de Janeiro: Vozes, 1980.

RAMOS, A. M. P. O Financiamento da educação brasileira no contexto das mudanças políticoeconômicas pós-90. Brasília: Plano, 2003.

SKIDMORE, T. Brasil: de Castelo a Tancredo. São Paulo: Paz e Terra, 2004. Brasil: de Getúlio a Castelo. São Paulo: Paz e Terra, 2003. 
SOUZA, M. C. C. A Formação dos partidos nacionais. In: FLEISCHER, D.V. (Org.). Os Partidos políticos no Brasil. Brasília: Editora da UnB, 1981, p.7-24. (Cadernos da UnB, v. 2) Estado e partidos políticos no Brasil (1930-1964). São Paulo: Alfa-Ômega, 1990.

Recebido em: maio 2007

Aprovado para publicação em: novembro 2007 